\title{
Corrigendum
}

\section{Corrigendum to "Experimental Study on Bond-Slip Behavior of Bamboo Bolt-Modified Slurry Interface under Pull-Out Load"}

\author{
Wei Lu (D), ${ }^{1,2}$ Dong Zhao, ${ }^{2}$ Xiao-fei Mao, ${ }^{2}$ and $\mathrm{Yu} \mathrm{Ai}^{3}$ \\ ${ }^{1}$ School of Civil Engineering, Xi'an University of Architecture \& Technology, Xi'an, Shaanxi 710055, China \\ ${ }^{2}$ School of Science, Xi'an University of Architecture \& Technology, Xi'an, Shaanxi 710055, China \\ ${ }^{3} X i$ 'an Aerospace Remote Sensing Data Technology Co., Ltd., Xi'an, Shaanxi 710100, China \\ Correspondence should be addressed to Wei Lu; woshidabaicai866@163.com
}

Received 2 August 2019; Accepted 2 August 2019; Published 21 January 2020

Copyright ( 92020 Wei Lu et al. This is an open access article distributed under the Creative Commons Attribution License, which permits unrestricted use, distribution, and reproduction in any medium, provided the original work is properly cited.

In the article titled "Experimental Study on Bond-Slip Behavior of Bamboo Bolt-Modified Slurry Interface under Pull-Out Load" [1], parts of the following article [2] were reproduced without citation or permission: $\mathrm{H}$. C. Biscaia, C. Chastre, I. S. Borba, C. Silva, D. Cruz, "Experimental evaluation of bonding between CFRP laminates and different structural materials," Journal of Composites for Construction 20 (3), 04015070 (https://ascelibrary.org/doi/ abs/10.1061/\%28ASCE\%29CC.1943-5614.0000631). The article has been corrected to cite this article.

Figure 19 in [1], showing the proposed bond-slip model, was taken from Figure 11 in Biscaia et al., and the functions were also reproduced: function (12) is the same as function (14) in Biscaia et al., (5)-(9) are the same as (7)-(11), (10) is the same as (18), and (13)-(14) are the same as (19)-(20). The authors retrospectively obtained permission from the American Society of Civil Engineers for reproduction of the figure. The figure legend has been corrected to state the source.

In affiliation 3, "Aerorspace" has been corrected to "Aerospace".

The authors apologize for this.

\section{References}

[1] W. Lu, Z. Dong, X.-F. Mao, and Y. Ai, "Experimental study on bond-slip behavior of bamboo bolt-modified slurry interface under pull-out load," Advances in Civil Engineering, vol. 2018, Article ID 6960285, 23 pages, 2018.

[2] H. C. Biscaia, C. Chastre, I. S. Borba, C. Silva, and D. Cruz, "Experimental evaluation of bonding between CFRP laminates and different structural materials," Journal of Composites for Construction, vol. 20, no. 3, Article ID 04015070, 2016. 


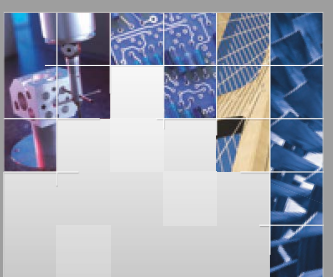

\section{Enfincering}
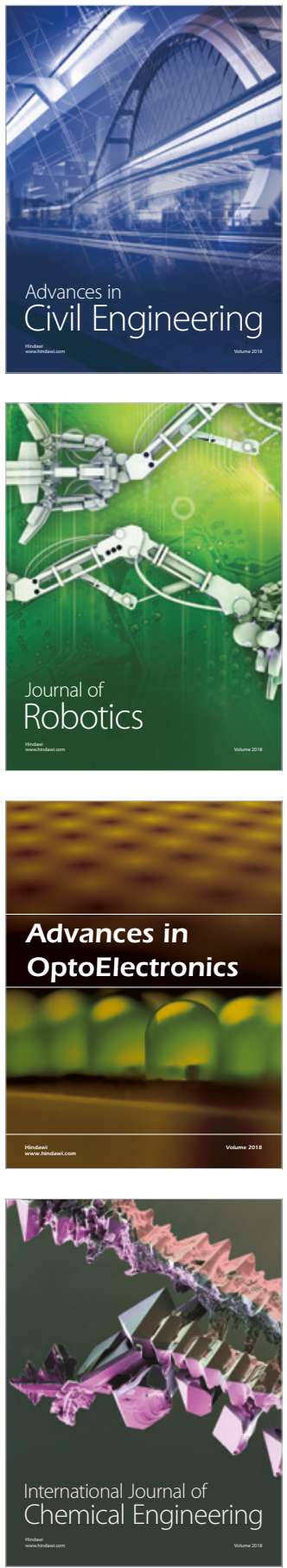

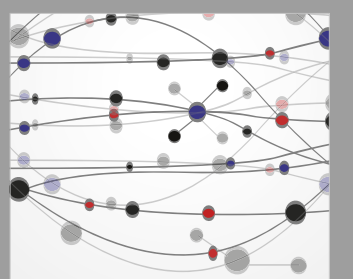

\section{Rotating \\ Machinery}

The Scientific World Journal

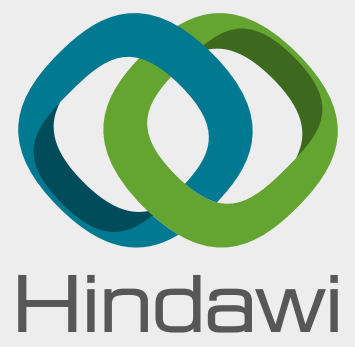

Submit your manuscripts at

www.hindawi.com
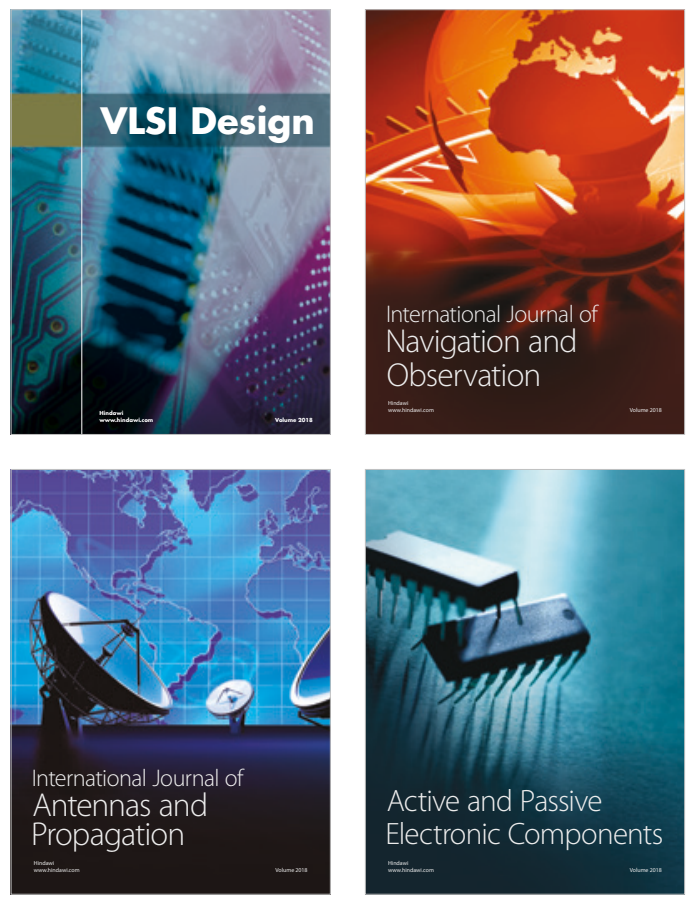
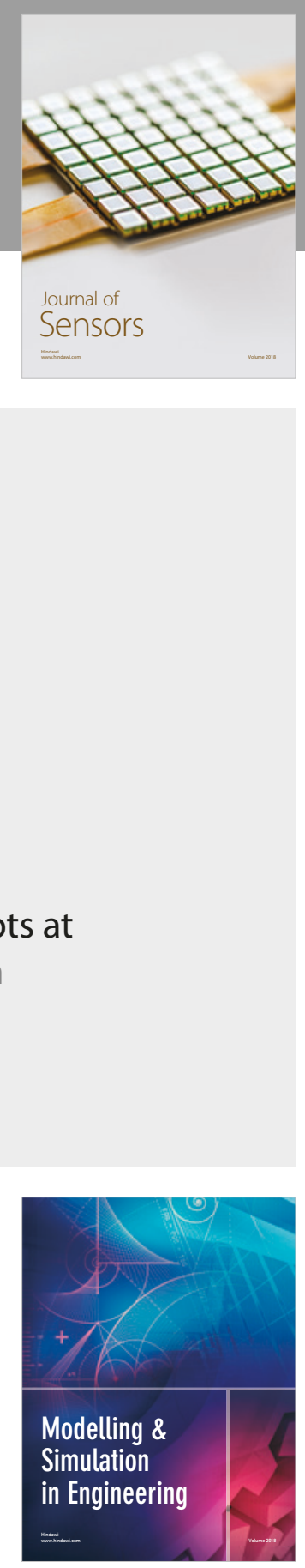

\section{Advances \\ Multimedia}
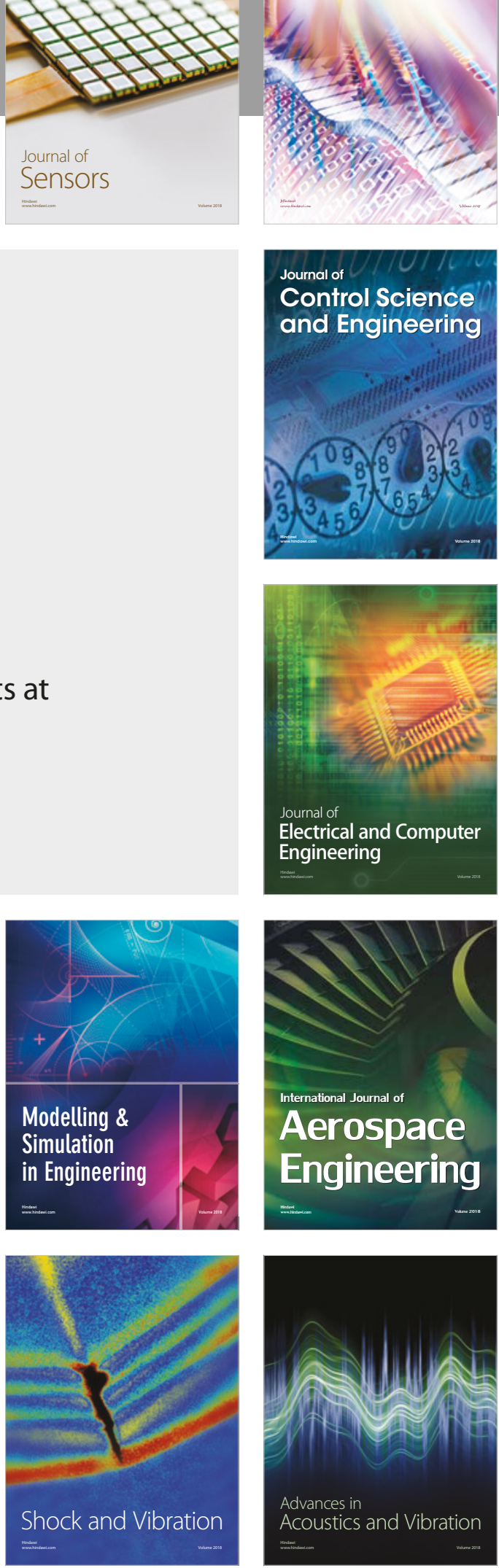